\title{
Derecho Marítimo
}

\section{Abordaje, Asistencia y Salvamento}

\author{
Por el Dr. GUILLERMO ELTON
}

\begin{abstract}
El doctor Jorge Arce Más, Catedrático de nuestra Universidad y Delegado a la IV Conferencia Interamericana de Abogados reunida recientemente en Santiago, nos ha proporcionado el interesante trabajo que publicamos a continuación. Su autor es el doctor Guillermo Elton, conocido abogado chileno y Catedrático de Derecho Comercial. El presente estudio fué presentado por-su autor a la Conferencia Interamericana de Abo. gados a que nos acabamos de referir.
\end{abstract}

Participando del anhelo mundial de universalización y difusión de los principios de derecho, en su más justa expresión, los abogados de América hemos cmprendido una activa tarea para adelantar en reuniones periódicas todo lo que concierne a nuestros países.

En esta Conferencia me ha correspondido representar, para el estudio de los abogados aquí reunidos, la conveniencia y practicabilidad de adaptar nuestras normas legales sobre abordaje, asistencia y salvamento a los principios aceptados, con la concurrencia de algunos paises americanos, en Bruselas, en Septiembre de 1910.

El Derecho Comercial es probablemente poco dúctil para adaptarse a las rápidas evoluciones de los conceptos jurídicos en nuestros tiempos, quizás porque representa los intereses económicos que son los que más se resis. ten a cambiar. A pesar de ello, se han abierto campo algunas ideas que sim. plifican y modernizan las normas mercantiles. Sin ir más allá, en las propias Conferencias anteriores de abogados, se ha aceptado el propósito, tan plausible, de suprimir esencialmente las diferencias entre asuntos civiles $y$ comerciales donde constituyen instituciones análogas. Este mismo camino no puede adoptarse, sin embargo, en numerosas cuestiones que, por su particularismo, requieren legislación especial; entre ellas podemos anotar el abordaje, la asistencia y salvamento, hechos y actos que aunque pueden ser so- 
lucionados, en los diversos problemas a que dan origen, por la legislación común, requieren más bien normas propias para evitar injusticias en la multitud de situaciones que se producen.

Enfocaré este trabajo considerando sólo algunos principales puntos juridicos en la forma en que son tratados por algunas legislaciones americanas $y$ por las Convenciones aprobadas en Bruselas.

\section{ABORDAJE}

Generalidades.-El choque o colisión de dos o más naves, ya se produzca por causa fortuita o por culpa de quienes las dirigen, constituye hoy un peligro $\tan$ frecuente de la navegación, que ha requerido una doble reglamentación, una preventiva y otra que se refiere a sus efectos. La primera, constituída principalmente por el Reglamento Internacional para prevenir Colisiones en el Mar, universalmente aceptado, sólo contiene disposiciones de policía maritima que quedan al margen de este estudio. La segunda, contiene normas propiamente de derecho, las que han evoluciỏnado desde su tratamiento como materia secundaria, cuando los medios de propulsión de las naves hacían este accidente caso de rara ocurrencia, para después despertar el interés de los juristas y legisladores la variación de dichas circunstancias, pero, traduciéndose él, en disposiciones engorrosas que han promovido discusiones o interpretaciones diversas, como las que existen en la mayoría de los países sud-americanos, y hoy día por último existe el áfán de encontrar reglas prácticas, basadas en el derecho común, que den una equitativa solución a todos los casos.

Aplicación.-Dos son los criterios para considerar la aplicación de las normas del Derecho Marítimo al abordaje. Uno estima el lugar donde se produce para decir que es abordaje marítimo el producido por el choque de naves en el mar o en ciertas radas y canales interiores de agua salada; es la doctrina aceptada por la antigua legislación francesa y en América, por las de Argentina. Brasil (ambos paises han aceptado después la Convención de Bruselas) y Chile, cuyo art. 861 del Código de Comercio lo hace aplicable sólo a la navegación marítima.

El segundo criterio sólo mira a la clase de barcos entre los cuales se produce el abordaje, sin distinguir si ha ocurrido en el mar o en aguas interiores, bastando la colisión de dos o más barcos, uno de los cuales sea de navegación marítima. Esta idea es la más generalmente aceptada hoy $\mathrm{y}$ ha sido incluida en las legislaciones belga, alemana, italiana y posteriormente adoptada en la Convención de Bruselas de 1910 y los paises que la han ratificado después. A mi entender es la solución más útil y racional ya que evita diferenciación en las normas que rigen casos similares por la sola circunstancia de que uno se produzca en el mar y otro en aguas interiores, problema que se agudiza cuando una misma expedición marítima tiene su iniciación o término en puertos fluviales o semi marítimos. Las grandes cuencas fluviales en América, de inmenso tráfico marítimo, hacen del todo punto necesario que se adopte el criterio de la Conferencia de Bruselas.

Consenso unánime ha existido siempre para no considerar abordaje marítimo el choque de una nave con un objeto fijo, como una mole, faro, etc., sino solamente el de dos embarcaciones, aunque una de ellas esté detenida, siempre que no lo sea en forma de destinación definitiva.

De los daños causados por el abordaje y su indemnización.-Generalmente para las partes interesadas en una expedición marítima constituirán 
averia particular por ser un hecho imprevisto; sin embargo, se puede concebir alguna situación en que el abordaje haya sido causado en forma inevita. ble por maniobras ordenadas por el capitán de una de las naves con el fin de salvar la expedición de un mal aparentemente mayor, siendo así una avería común.

En cualquiera de los dos casos, pero particularmente en el primero, interesa dilucidar quién será el último responsable de los daños causados en este accidente maritimo.

Aunque es ésta una cuestión que puede ser entregada, en su apreciación, a los principios sobre responsabilidad extracontractual e indemnización de perjuicios que existen en la legislación civil, como lo era en tiempos de los romanos, la infinidad de casos que existen, que pueden derivar en situación bien injusta considerando la cuantía de los intereses comprometidos, han hecho que los juristas de todos los tiempos se hayan preocupado de encontrar en lo posible soluciones adecuadas a todos ellos en un plano de equidad. En la Edad Media, la idea de mutualidad que abarcaba incluso la rama del Derecho Maritimo influyó para que se aceptara que los daños del abordaje fueran repartidos entre los dueños de las naves y mercaderías afectadas en una especie de liquidación de avería común. No siendo esta tendencia sino la expresión de una época, las compilaciones y legislaciones posteriores fueron evoluciónando en contra de ella hasta poder, Emerigon, en Francia, enunciar la doctrina de la triple clasificación del abordaje en fortuito, culpable y dudoso o mixto, cuyas definiciones, por ser suscintas, se comprendian claramente en el que fué el art. 407 del Código de Comercio francés que decía como sigue: "Si el abordaje es puramente fortuito, el daño es soportado, sin repetición, por el navio que lo ha sufrido. Si el abordaje ha sido provocado por la falta de uno de los capitanes, el daño es pagado por aquél que lo ha causado. Si existe duda en las causas del abordaje, el perjuicio es reparado en común y por partes iguales por las naves que los han causado y sufrido".

Los dos primeros casos de abordaje, el fortuito y el culpable, son sim. plemente la expresión de las normas generales de derecho según las cuales. cada uno soporta los daños que por caso fortuito se produzcan en su propiedad y responde de los causados por su propia culpa.

El abordaje fortuito existirá siempre que no se pruebe culpa de alguno o todos los que han intervenido, de manera que es la regla general que no necesita probarse. Algunas legislaciones, sin embargo, han establecido ciertos casos de presunciones de culpabilidad, particularmente cuando hay infracciones a las normas de policía marítima, invirtiendo asi el peso de la prueba; así, el Código de Comercio chileno en su art. 1134 establece cinco casos de presunciones legales; también tienen disposiciones en este sentido una ley de los Estados Unidos de Norte América, el Código Portugués y los Códigos Escandinavos. No existen presunciones de culpabilidad en las leyes argentinas, brasileras y peruanas. La Convención de Bruselas de 1910, inspirada en el ánimo de dejar a los jueces el libre análisis de cada caso-que siempre tendrá sus particularidades- suprime toda idea de presunción legal.

El abordaje culpable hace recaer la indemnización de los perjuicios en la persona del capitán por cuya negligencia o intención se produjo, siendo indiferente para este efecto que en aquel momento la nave estuviera bajo la inmediata dirección de un práctico; pero la dificultad ha surgido para el caso en que ambos o todos los capitanes sean culpables, circunstancia para la cual se han ideado tres soluciones: a) algunos pretenden que cada cual 
deberá soportar sus daños, estableciendo así una especie de compensación de las culpas recíprocas; b) otros sostienen, como un método meramente práctico de anular la dificultad. que los daños deben sumarse y dividirse después por mitades, proporción en la que los soportarán las partes -era ésta la teoría de Inglaterra y los Estados Unidos; c) por último, en aquellos paises en que no existía una norma especial al respecto, se ha interpretado el derecho en el sentido que los perjuicios cieberán ser indemnizados por los respectivos capitanes en proporción de su grado de culpabilidad en el hecho. A pesar que esta solución presenta la dificultad de hecho de esta última apreciación, difícil por su naturaleza, atendiendo a que ella es la aplicación ri. gurosa del derecho, evitando las posibles injusticias de un repartimiento del valor de los daños que puede estar alejado del grado de culpabilidad e incluso de la capacidad económica de quien debe soportarlo, ha sido hoy aceptada por la mayoría. En América, las legislaciones peruanas y chilenas adoptan aun la primera teoría; la brasilera no se pronuncia. La Convención de Bruselas, en su art. 4\%, adopta la última de ellas, pero en el caso en que sea imposible déterminar el grado de culpa de cada parte, o ésta resulte equivalente, los perjuicios se distribuyen por mitad. Se mantiene asi el principio de derecho dentro de las posibilidades de su aplicación práctica.

La interpretación de lo que es abordaje dudoso o mixto y de su legitimidad han dado origen a discusiones y críticas. Las primeras en cuanto a su existencia misma, esto es si el abordaje es dudoso cuando se desconoce su causa o solamente cuando, sabiéndose culpable, es imposible atribuir la negligencia en particular a cualquiera de los que han intervenido; en algunos países en que expresamente existe una disposición que presume fortuita la colisión, como en Chile, esto último es lo único aceptable. Críticas se han suscitado atacando de injusto el repartimiento de los daños en el abordaje dudoso, por. partes iguales, ya que él puede desconocer la realidad de los hechos al castigar a un inocente o afectar a las partes desproporcionadamente si los barcos que han entrado en colisión son de distinto tamaño, representando capitales diversos, pudiendo el menor tener que soportar perjuicios que representen más que su propio valor.

Estos $y$ otros inconvenientes hacen que la institución del abordaje dudoso haya devenido un concepto artificial, desaparecido ya de las legislaciones, salvo algunas que conservan sus principios antiguos, entre cllas, la chilena. La Convención de Bruselas de 1910, aceptada en casi todos los paises marítimos europeos y varios americanos, tampoco lo contempla.

Dicho acuerdo; adoptado en 1910, ha dejado claramente establecido que todas sus disposiciones referidas, sobre indemnización de los perjuicios causados por el abordaje marítimo, se aplican, tanto a los sufridos por la nave, como por las mercaderias, tripulación y pasajeros. supliendo así el silencio de casi todas las legislaciones respecto de estos últimos. quienes carecían en esta forma de toda protección especial al respecto, omisión ciertamente de bida al espíritu netamente mercantilista que ha informado las legislaciones comerciales hasta ahora. Más aun, para el caso de heridas o muertes de personas de a bordo, que den origen a indemnización en el abordaje culpable, por parte de dos o más barcos, la Convención de Bruselas, constituye a sus propietarios soliclariamente responsables por ella, a diferencia de la indem. nización de los daños a naves y mercaderías; pero como esta disposición se ha prestado a críticas en cuanto el que paga más de lo que le empoce, obligado por su responsabilidad solidaria, puede encontrarse después, al repetir por el exceso en contra de sus otros co-deudores, que su acción no puede prosperar, ya sca porque hacen valer el abandono o cláusulas contractuales 
eximentes de responsabilidad, se ha dejado a las leyes nacionales la determinación de la mejor forma de evitar esta desigual carga de los perjuicios.

Acciones de indemnización.-Con el fin de hacer más expedito y seguro el cobro de las indemnizaciones mencionadas, sobre cuyo monto no se pronunció la Convención de 1910 aceptando así, tácitamente, el derecho general según el cual comprenden el daño emergente y lucro cesante, aquella acordó la supresión de la fórmula o trámite de la protesta sobre los daños que la mayoría de las legislaciones admiten como necesaria para conservar la acción, probablemente estimando que ella es una constancia inmediata de lo ocurrido, la que puede contribuir en algo al resguardo de los intereses, muchas veces considerables, comprometidos en una expedición marítima, evitando posibles fraudes al respecto. En verdad las protestas que deben hacer los capitanes o cargadores en varias ocasiones de la navegación, han llegado a ser una ritualidad sin mayor beneficio, ya que los libros de la nave y el control de las marinas mercantes por las autoridades, las reemplazan ventajosamente y en cambio con su supresión se evita que una acción caduque por el simple hecho de no cumplirse con una fórmula en ocasiones difícil de llenar.

En cambio se generaliza por la Convención un plazo de prescripción de dos años, a contar del accidente, para el reclamo de los perjuicios, y otro de un año, a contar del pago, para repetir en contra de los demás responsables por aquel co-deudor que ha pagado en virtud de su obligación en el caso que he mencionado de accidente a las personas.

La Convención no se ha referido directamente a ningún privilegio de carácter real sobre el barco responsable para perseguir el cobro del daño, dejando en este punto subsistentes las legislaciones particulares.

Unificación de las legislaciones.-La Convención de Bruselas de 1910 sobre el abordaje, fué el producto de un maduro estudio de años por parte de juristas y asociaciones interesadas en la materia. Concurrieron a ella las siguientes 23 naciones: Alemania, Argentina, Austria-Hungría, Bélgica, Brasil, Chile, Cuba. Dinamarca, España, Estados Unidos, Francia, Holanda, Inglaterra, Grecia, Italia, Japón, Méjico, Nicaragua, Noruega, Portugal, Rumania, Rusia y Uruguay. El texto del acuerdo es el que sigue:

"Art, 1".-En caso de abordaje sobrevenido entre buques de mar, o entre buques de mar y barcos de navegación interior, las indemnizaciones de. bidas a consecuencia de los daños causados a los buques y a las cosas o personas que se hallaren a bordo, serán reguladas conforme a las disposiciones siguientes, sin que deba tenerse en cuenta las aguas en que el abordaje se haya producido".

"Art. 2"-Si el abordaje es fortuito o debido a un caso de fuerza mayor o existiese duda acerca de las causas del abordaje, los daños serán de cargo de quienes los hayan experimentado".

"Esta disposición será aplicable también en el caso de que los buques o uno solo de ellos esté fondeado en el momento del accidente".

"Art. $3^{\circ}$.- Si el abordaje es debido a falta cometida por uno de los buques, la reparación del daño incumbe al que lo ha causado".

"Art. 4\%.-Si la falta es común. la responsabilidad de cada uno de los buques es proporcional a la gravedad de las faltas respectivamente cometidas; pero si, a pesar de ello y según las circunstancias, la proporción no pudiera. establecerse o aparecieran las faltas como equivalentes, la responsabilidad se dividirá por iguales partes".

"Los daños causados, bien a los buques, bien a sus cargamentos, bien a los efectos u otros bienes de la tripulación, de los pasajeros o de otras per- 
sonas que se hallaren a bordo, serán de cargo de los buques culpables, en la dicha proporción, sin solidaridad respecto de terceros".

"Los buques responsables responden asimismo solidariamente respecto de terceros, de los perjuicios causados por muerte o heridas, salvo el recurso del que ha pagadoana parte superior a la que, conforme a lo dispues. to en el primer párrafo del presente artículo, deba definitivamente soportar".

"Incumbe a las legislaciones nacionales la determinación, en lo que concierne a este recurso, del sentido y los efectos de las disposiciones contractuales o legales que limitan la responsabilidad de los propietarios de los buques respecto de las personas que se hallasen a bordo".

- "Art. 5\%.-La responsabilidad establecida en los precedentes artículos subsiste en el caso de que el abordaje ocurra por falta del piloto, aun en el caso de ser su empleo obligatorio".

"Art. 6".-La acción en reparación de daños sufridos a consecuencia de un abordaje no está subordinada a ningún protesto ni a ninguna otra formalidad especial".

"No habrá lugar a considerar presunciones legales de falta en cuanto a la responsabilidad del abordaje".

"Art. 7".-Las acciones en reparación de los daños prescribirán a los dos años, a partir del accidente".

"El plazo para intentar las acciones admitidas en el párrafo tercero del art. $4^{\circ}$ será de un año. Esta prescripción no correrá sino desde el día del pago".

"Las causas de suspensión y de interrupción de estas prescripciones serán determinadas por la ley del tribunal que entiende de la acción".

"Las Altas Partes contratantes se reservan el derecho de admitir en sus legislaciones, como prórroga de los plazos arriba fijados, el hecho de que el buque demandado no haya podido ser embargado en las aguas territoriales del Estado en el cual el demandante tiene su domicilio o bien su principal establecimiento".

"Art. 8\%.-Después de un abordaje. el capitán de cada uno de los buques entrados en colisión está obligado, en tanto pueda hacerlo sin peligro serio para su buque, para su tripulación o sus pasajeros, a prestar asistencia al otro buque, a su tripulación y pasajeros".

"Está obligado también, en la medida de lo posible, a dar a conocer al otro buque el nombre o lugar de su inscripción, así como los puntos de donde procede y a donde se dirige".

"El propietario del buque no será responsable de la contravención a las precedentes disposiciones".

"Art. 9\%--Las Altas Partes contratantes cuya legislación no reprima las infracciones del articulo precedente. se obligan a tomar o proponer a sus Cuerpos Colegisladores respectivos las medidas necesarias para que dichas infracciones sean reprimidas".

"Las Altas Partes contratantes se comunicarán, tan luego como pue. dan hacerlo, las leyes y reglamentos que habrán ya dictado o que dicten en lo sucesivo en sus Estados para el cumplimiento de la disposición precedente".

"Art. 10.-A reserva de ulteriores Convenios, se estatuye que las presentes disposiciones no afectan a las reglas establecidas sobre limitación de la responsabilidad de los propietarios de buques, como tampoco a las obligaciones resultantes del contrato de transporte o de todos los demás contratos".

"Art. 11.-El presente Convenio no es aplicable a los buques de guerra ni a los del Estado exclusivamente afectos a un servicio público". 
"Art. 12.-Las disposiciones de la presente Convención tendrán aplicación a todos los interesados cuando los buques de referencia pertenezcan a los Estados de las Altas Partes contratantes y en los demás casos previstos por las leyes nacionales".

"Queda entendido en todo caso:

"1\%.-Que respecto de los interesados pertenecientes a un Estado no contratante, la aplicación de dichas disposiciones podrá subordinarse por cada uno de los Estados contratantes a la condición de reciprocidad".

"2"-Que cuando todos los interesados pertenezcan al mismo Estado que el Tribunal que juzga, será la ley nacional y no el Convenio lo aplicable".

"Art. 13.-El presente Convenio se extiende a la reparación de daños que, sea por ejecución, sea omisión de una maniobra, sea por inobservancia de Reglamentos, un buque cause a otro buque, o bien a cosas o personas que se nallen a bordo, aun en el caso de no haber habido abordaje".

"Art. 14.-Cada una de las partes contratantes tendrá la facultad de motivar la reunión de una nueva Conferencia, a los tres años de entrar en vigor el Convenio presente, con el objeto de buscar las mejoras que puedan introducirse $y$, principalmente, extencler la esfera de su aplicación".

"La Potencia que haga uso de esta facultad deberá notificar la intención a las otras potencias por intermedio del Gobierno belga, que se encargará de convocar la Conferencia a los seis meses".

"Art. 15.-Los Estados que no han firmado el presente Convenio podrán adherirse a él si lo pidieran".

"Esta adhesión será notificada por la vía diplomática al Gobierno belga, y por éste a cada uno de los Gobiernos de las otras partes contratantes, surtiendo sus efectos un mes después de las notificaciones hechas por el Gobierno belga".

"Art. 16.-El presente Convenio será ratificado: A la expiración del plazo de un año, lo más tarde, a contar del día de su firma, en que el Gobierno belga entrará en relación con los Gobiernos de las Altas Partes contratantes que se hubiesen declarado dispuestas a ratificarlo, al objeto de decidir si hay lugar a ponerlo en vigor".

"Las ratificaciones, llegado el caso, se depositarán inmediatamente en Bruselas, y el Convenio producirá sus efectos un mes después del depósito".

"El protocolo permanecerá abierto un año más en favor de los Estados representados en la Conferencia de Bruselas".

"Art. 17.-En el caso de que una u otra de las Altas Partes contratantes denunciara el presente Convenio, esta denuncia no producirá sus efectos hasta un año después ciel dia en que hubiere sido notificada al Gobierno belga, y el Convenio continuará rigiendo entre las demás partes contratantes".

"Artículo adicional.-Por derogación del art. 16 que precede, se entiende que la disposición del art. $5^{\circ}$, fijando la responsabilidad en los casos de abordaje causado por falta debida a piloto obligatorio, no entrará en pleno derecho en vigor hasta que las partes contratantes se hayan puesto de acuerdo para la limitación de la responsabilidad de los propietarios de buques".

"Bruselas, 23 de Setiembre de 1910".

Del contexto anterior, así como de la relación que he hecho, podemos notar que la Convención de Bruselas reglamenta en una forma sencilla, equitativa y práctica, las cuestiones fundamentales a que da origen el abordaje, dejando subsistentes las legislaciones nacionales en todo aquello que signi- 
fica conexión con otros puntos del derecho común o especial que no conviene tocar.

El abordaje da origen a conflictos internacionales por la diferente nacionalidad de los intereses que pueden estar comprometidos en él, y los distintos lugares en que puede ocurrir. A su más fácil solución contribuirá, cier. tamente, una legislación común universal, legislación hacia la cual el paso más avanzado hoy día es aquella Convención, ya aceptada e incluída en las legislaciones de la mayoría de los paises marítimos europeos. En América, principalmente la Latina, hemos sido tardos en considerar las reformas y adaptaciones de nuestra legislación comercial marítima, probablemente porque nuestro comercio de esta especie sólo ha tomado incremento en los úl. timos años. De los siete países participantes en la Conferencia de Bruselas, sólo he podido constatar que Brasil, por decreto del 18 de Febrero de 1914, ratificó la Convención.

La consideración del desarrollo qué prometen tomar las marinas mercantes de nuestros países en este período de post-guerra debe hacernos acelerar el estudio de las reformas que reclaman nuestras leyes y la adopción de los principios comunes, como la Convención de Bruselas, que ya han sido aceptados en los países de otras partes del mundo; esta reforma deberá hacerse, creo yo, no sólo mediante la simple ratificación de dicho acuerdo, sino incorporándolo en la legislación mediante su reforma; de esta manera no sólo constituirá simples reglas de Derecho Internacional Privado, sino también la legislación nacional misma, evitando la dualidad y complicación de ésta, mayormente cuando la de los países sud-americanos en su mayoría no representa tradiciones o necesidadies propias de cada uno, sino que ha sido pedida prestada, en fiel copia, a algunos países europeos.

\section{ASISTENCIA Y SALVAMENTO}

La Conferencia de Bruselas de 1910 se ocupó también de esta materia, habiéndose aprobado otra Convención al respecto.

Características.-La primera cuestión que ha promovido amplias discusiones se refiere a la diferencia que existiría entre los términos y casos de asistencia y salvamento o si en el hecho, y para su consideración jurídica, éstos son una misma cosa. El criterio inglés no hace distinción alguna y habla solamente de salvamento: se salva a un barco que está en peligro, del riesgo le perecer, o se salvan restos náufrágos de su destrucción y comple. to aniquilamiento; en ambos casos existe fundamentalmente el mismo acto, la recuperación de un navío o sus restos de su destrucción por riesgo de mar. La doctrina francesa y de otros autores, en cambio, ve dos cosas diversas en la asistencia y salvamento, que diferencian desde luego fundamentalmente en que la primera es siempre una convención entre partes referente al salvamento de un navío de un peligro actualmente inminente pero al cual aun no ha sucumbido; en cambio el salvamento es corrientemente un acto unilateral por el que los salvadores rescatan especies náufragas.

Ambas corrientes han unificado hoy hasta cierto punto sus discrepancias aceptando que unas normas comunes pueden dictarse respecto de una serie de cuestiones básicas a que dan origen estos hechos y actos similares de la asistencia y salvamento; así, una misma será la legislación que distinguirá cuándo existe un caso de asistencia o salvamento; quiénes son salvadores, cuál es su derecho de remuneración, etc. Esta es la orientación que ha dado al asunto la Convención adoptada en Bruselas en 1910, la cual llegó a hacer una declaración enfática en el sentido que no existe tal diferencia, 
la cual, por su carácter general y su falta de necesidad, ha sido eliminada en algunos países que concurrieron al acuerdo.

Aplicación.-El mismo principio que pata el abordaje ha admitido la Convención de Bruselas para la Asistencia y Salvamento, estatuyendo que ella se aplicará a todo barco en peligro que sea de navegación marítima o siempre que los servicios de asistencia y salvamento se presten entre barcos de dicha clase y otros de navegación interna, cualquiera que sean las aguas donde se realicen.

Obligatoriedad de la Asistencia.-Ha existido diversidad en las legislaciones respecto de la aceptación de la asistencia a naves o personas en peligro en el mar como una obligación. El Código marítimo italiano la ha establecido en su forma más amplia al estatuír que "El capitán de un barco na. cional que encuentre a otro cualquiera, aun extranjero o enemigo, en peligro de perderse, debe acudir en su ayuda y prestarle toda la asistencia posible". Los preceptos generalmente aceptacios en otros países son bastante más res. tringidos que éste. Desde luego la Convención de Bruselas sobre Asistencia y Salvamento acuerda que todo capitán está obligado, mientras lo pueda hacer sin peligro para su buque, equipaje y pasajeros, a prestar asistencia a toda persona, aun enemiga, hallada en el mar en peligro de sucumbir. Esta disposición obliga solamente a asistir a las personas en peligro y no a las naves y mercaderias; es contraria por ello a la solidaridad que debe existir en el Derecho Marítimo. La única disposición que se aceptó en la ciudad belga sobre auxilio de los barcos la encontramos en la Convención sobre abordaje que obliga a un capitán de un barco que entre en colisión con otro, a prestarle asistencia así como a su tripulación y pasajeros, siempre que en esta operación no corra serio peligro su propio barco, equipaje y pasajeros, dejando entregada a las legislaciones nacionales la sanción como delito a la contravención de este deber. En Amlérica, entre otras, las legislaciones argentina y chilena establecen la obligatoriedad de la asistencia incluso para las naves.

La Convención de Bruselas, así como muchas normas nacionales de di. versos paises habla de la asistencia como obligatoria para "el capitán que encuentre a un barco en peligro", y si interpretamos esta disposición, como al guno ha pretendido, en forma estricta, tendríamos que aceptar, como dice Ripert, que sólo debe auxiliarse a los barcos en peligro que aparezcan a la vista del auxiliador, dejando fuera de uso para estos efectos a la telegrafía sin hilos. Sin duda que el objeto de la norma establecida en 1910 y el espíritu de sus forjadores no ha sido éste y si un capitán recibe un llamamiento de ayuda por telegrafía inalámbrica, deberá acudir en auxilio siempre que su prudencia y conocimientos le indiquen que sus servicios, en atención a la distancia, serán ủtiles. La dificultad que se presentará para sancionar a un capitán infractor en este caso enicuanto su dolo o negligencia sólo podrán determinarse mediante la apreciación de su fuero interno en aquél momento, no es óbice para que se acepte un principid que es de justicia y utilidad en la navegación mundial.

La Convención de Bruselas elimina al naviero de la responsabilidad que pueda caber al capitán por infringir la anterior obligación; si esto está bien en cuanto a la pena personal que le pueda corresponder por su delito, no es lo mismo si existe una condena por indemnización civil que debería también responsabilizar al naviero como las demás acciones de este carácter en el Derecho Marítimo.

Quiénes son salvadores.-Lo serán todas aquellas personas extrañas al servicio de la nave que le presten un servicio útil para precaverla de un peli- 
gro o rescatarla en todo o en parte de su completa destrucción. Estas personas tendrán derecho a un premio o retribución por sus servicios prestados.

a).-De manera que para que exista asistencia o salvamento, que den a sus autores derecho a remuneración, debe haber primeramente un re-sultado útil; es éste un principio universalmente aceptado aunque representa una injusticia en cuanto estas empresas pueden demandar ingentes gastos y peligros que no tendrán ningún pago de no obtenerse resultado feliz; de aquí, que, en compensación, el premio del salvamento sea considerable. Este principio se repite en la Convención de Bruselas de 1910 , en su art. $2^{\circ}$, indicando que "no se debe remuneración alguna en caso de que el socorro prestado quedase sin resultado útil".

b).-En seguida, se requiere que la asistencia o salvamento se pres. ten con la aquiescencia del capitán o naviero del buque socorrido, ya que és. tos son los primeramente obligados a auxiliar a su nave y sin su consentimiento no podrán verse obligados a pagar servicios que no han solicitado por estimarlos innecesarios. Es también una disposición incluída en la Convención de Bruselas.

c).-No tienen el carácter de salvadores los oficiales y tripulantes de un barco en cuanto le prestan auxilio especial en caso de peligro, ya que estas faenas caen dentro de su obligación contractual. Sin embargo, en algunos casos especiales se ha estimado que son acreedores al premio especial, como salvadores, aquellos tripulantes, va formen la totalidad o parte de una dotación, que, después de haber abandonado su nave en peligro por orden. del capitán, quien ha estimado imposible conservarła, emprenden con éxito la tarea de su salvamento.

d). -Objeto de especial consideración ha sido el caso del remolcador, por si puede constituírse en salvador de la nave remolcada durante el cumplimiento de su cometido. No se trata aquí del remolque especialmente contratado para una nave en peligro que constituye una convención especial de asistencia y debe ser tratada como tal, sino del caso imprevisto ocurrido en el cumplimiento de un contrato corriente. Los ingleses han enfocado este problema desde un punto de vista práctico y lógico al decir que el remolcador tendrá derecho a remuneración especial de salvamento sólo en el caso que los servicios especiales que rinda, en asistencia de la nave remol. cada que se encuentra en peligro "estén más allá de lo que razonablemente se pueda suponer como contemplado por las partes dentro del contrato de remolque". Es decir que no son salvamento los actos de ayuda que se presten, por ejemplo en un caso de temporal ocurrido durante la navegación, pero sí lo serán cuando en esta misma situación el peligro viene por el mal estado de la nave remolcada y que el remolcador no pudo conocer. Es el principionque acepta en su art. $4^{\circ}$ la Convención de 1910.

e).-La Convención de Bruselas ha dejado subsistentes las legislaciones nacionales $\mathbf{u}$ otros pactos entre naciones respecto de la existencia $\mathbf{y}$ derechos de servicios públicos de salvamento o aquél prestado por las naves de guerra de un Estado.

La mayoría de las legislaciones establecen que los miembros de servicios públicos de salvamento no tienen derecho a un premio especial por cada caso en que actúan, al menos en los salvamentos de personas.

Más divididas están las opiniones en cuanto a los servicios de este carácter prestados por los buques de guerra. Las legislaciones inglesa y francesa, más bien impulsadas yor las necesidades de la Primera Guerra Mundial que acarreó la multiplicación de las catástrofes marítimas, conceden este

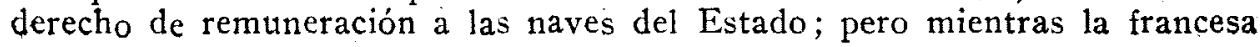


lo niega particularmente a los marinos que han intervenido, quienes cuando más pueden recibir una gratificación voluntaria, la inglesa lo concede aún a los marinos personalmente, bajo la única condición que para el cobro requieren la autorización del Almirantazgo.

En América, la legislación chilena prohibe a las personas de la autoridad pública recibir gratificaciones de.salvamento, sino únicamente los gastos; era lo que sostenía la legislación francesa antigua. No he hallado disposiciones particulares sobre este punto en las leyes de Brasil, Perú y Argentina.

Remuneración de la asistencia y salvamento.-Hemos visto que todo acto útil de asistencia o salvamento da derecho a una remuneración para sus actores siempre que se cumplan los requisitos anteriores. Esta remuneración podrá tener un origen contractual en caso que haya habido una convención previa entre las partes o en la ley que la ordena si aquel acuerdo no ha existido; en todo caso ella es exigida por la equidad que impone remunerar servicios, generalmente costosos y peligrosos, y que significan para sus benéficiarios la conservación o recuperación de cuantiosos intereses.

Los principios modernos tienden a suprimir las antiguas prácticas del pago en especie sobre los propios objetos salvados de la prima o gratificación de salvamento, esto aun para el caso de rescate de restos náufragos, es decir que se suprime la tendencia generalizada en derecho de aceptar la adquisición del dominio sobre las especies náufragas por sus extractores, mediante la ocupación como un verdadero modo especial de adquirirlo. Se ha dicho que esta práctica es inconveniente y anti-jurídica. Lo primero porque, agudizándola, llegamos al sistema de pillaje y bandolerismo de la Edad Media y principios de la Moderna en que se llegó a establecer el lucrativo negocio de provocar naufragios para aprovecharse de sus restos. Lo segundo, porque las naves o sus restos y las mercaderías no dejan de tener dueño porque arriban destrozadas a las costas y momentáneamente no hay quien se presente a reclamar su propiedad. Ante esta situación se pretende ahora que en todo caso los salvadores sólo tienen derecho al pago de una suma en dinero, ya se las cancele el propietario que se presenta a recuperar sus bienes, ya el Es. tado que toma sobre sí la reglamentación y truición de la denuncia, extracción y conservación de las especies náufragas y para procurarse las sumas necesarias a ello rematará en pública subasta los bienes que sean necesarios, siempre que no esté presente el dueño; para el caso en que éste no sea habido durante un lapso cuya duración cada legislación determinará prudencialmente, el Estado se hará dueño de los restos o del remanente de su producto en remate; algunos sostienen que aquí el Estado adquiere por prescripción, pero puede mantenerse también que su dominio viene directamente del mandato de la ley en razón de utilidad pública.

El monto de la remuneración que corresponde a los salvadores será determinado pór la Convención o el juez y se basará en una proporción del valor de los objetos salvados. La Convención de Bruselas establece que nunca deberá sobrepasar el valor total de ellos y se comprende esta disposición ya que en dicho caso dejaría de existir un resultado útil en los servicios. Pdra el caso en que haya existido una Convención previa de asistencia, principalmente, o salvamento, puede ella adolecer de abuso por una parte en cuanto podría haberse aprovechado de la situación apremiante del asistido para exigir una remuneración desproporcionada. En ausencia de ley al respecto muchas han sido las opiniones vertdas por los autores para justificar una revisión del monto de la remuneración así acordada, algunos han pretendido que no puede existir consentimiento alguno ante la situación de peligro, otros 
que el aprovecharse de éste constituye una verdadera fuerza que vicia el con. sentimiento, unos terceros que la asistencia constituye un contrato "sui géneris" del Derecho Marítimo que autoriza la revisión, también que constitatuyen expresamente que el juè podrá anular o modificar la remuneración Pero la Convención de Bruselas y las legislaciones que la han seguido, estatuye expresamente que el juez podrá anular o modificar la remuneración fijada por las partes cuando ha existido dolo o cuando ella sea excesiva, ya sea por alta o por baja, determinándola en su justo término.

Para fijar la cantidad que corresponda a los salvadores por premio de su intervención, el juez deberá tener presente por una parte el resultado obtenido, los esfuerzos, gastos y riesgos puestos en acción por los que han prestado socorro y el peligro corrido por los asistidos, y por otra el valor de los objetos salvados.

La Convención de Bruselas acepta el criterio de no acordar remuneración alguna a los salvadores de vidas humanas y sólo en cuanto éstos hubieren intervenido asimismo en el rescate de la nave y su mercaderia. Este principio ha sido blanco de objeciones ya que el que asiste a las personas puede arriesgar tanto o más su propia vida como los que lo hacen respecto de la nave o mercaderías y los gastos y materiales necesarios para la operación serán asimismo equivalentes. Por otra parte puede resolverse en una falta de estímulo para el salvamento de las personas con el consiguiente ries. go de éstas.

Acción de cobro.-La Convención de Bruselas admite también, al igual que para el abordaje, un plazo de prescripción de dos años en los que caducará la acción por pago de la remuneración y los que se contarán desde la fe. cha de terminación de los servicios prestados.

Legislaciones americanas.-Nuestras legislaciones son asimismo confusas para reglamentar las operaciones de asistencia y salvamento y sus efectos. Cortas disposiciones existen en Brasil y Argentina; ninguna especial en el Código de Comercio del Perú y varias diseminadas en diversos Códigos y leyes en Chile. Esto, unido a la necesidad y ventaja de tener normas claras que reglamenten y estimulen estas operaciones de salvamento en provecho exclusivo de la seguridad de la navegación marítima que se traduce en resguardo de los intereses económicos y vidas comprometidas, requiere que estudiemos y adoptemos la Convención aceptada el 23 de Setiembre de 1910 en la capital belga.

$\mathrm{Su}$ texto es el siguiente:

"Art. 1". La asistencia y el salvataje de los buques de mar en peligro. de los objetos que se hallaren a bordo, del flete y del precio del pasaje, así como los servicios de la misma naturaleza prestados entre buques de mar y embarcaciones de navegación interna quedan sometidos a las disposiciones siguientes, sin que haya distinción y sin que haya que tener en cuenta las aguas en que hubiesen sido prestados".

"Art. 2". - Todo hecho de asistencia entre ambas clases de embarcaciones o de salvataje que hubiere tenido un resultado útil da lugar a una remuneración equitativa".

"No se debe remuneración alguna en caso de que el socorro prestado quedase sin resultado útil".

"En ningún caso puede pasar la suma a pagarse del valor de los obje_ tos salvados".

"Art. 3"-No tienen derecho a remuneración alguna las personas que hubiesen tomado parte en las operaciones de socorro a pesar de la defensa ex. presa y razonable del buque socorrido". 
"Art. 4"-El remolcador sólo tiene derecho a una remuneración por la asistencia o el salvataje del buque por él remolcado o de su cargamento en caso de que hubiera prestado servicios excepcionales que no pundan ser considerados como el cumplimiento del contrato de remolque".

"Art. 5".-También se debe una remuneración en caso de que la asistencia o el salvataje se-hubiera realizado entre buques pertenecientes al mismo propietario".

"Art. 6\%.-El importe de la remuneración queda fijado por convenio de las partes $y$, en su defecto, por el juez".

"Sucede lo mismo respecto a la proporción en que esta remuneración debe ser repartida entre los salvadores".

"La repartición entre el propietario, el capitán y las demás personas al servicio de cada uno de los buques salvadores será determinada por la ley nacional del buque".

"Art. $7^{\circ}$ - - Toda convención de asistencia o salvataje efectuada en el momento y bajo la influencia del peligro, a requerimiento de una de las partes, puede ser anulada o modificada por el juez, en caso que estimara que las condiciones convenidas no son equitativas".

"En todos los casos, cuando se ha comprobado que el consentimiento de una de las partes ha sido viciado por dolo, reticencia o cuando la remuneración está, de manera excesiva en uno u otro sentido, en desproporción con el servicio prestado, la convención puede, a requerimiento de la parte interesada, ser anulada o modificada por el juez”.

“Art. 8\%.-La remuneración queda determinada por el juez según las cir-. cunstancias, tomando por base: a) en primer lugar el éxito obtenido, los esfuerźos y el mérito de los que hubieren prestado socorro, el peligro corrido por el buque asistido, sus pasajeros y su tripulación, por su cargamento, por los salvadores y el buque saivador, el tiempo empleado, los gastos y perjuicios sufridos y los riesgos corridos por los salvadores, el valor del material expuesto por ellos, teniendo en cuenta, dado el caso, la apropiación especial del buque asistente; b) en segundo lugar el valor de los objetos salvados".

"Las mismas disposiciones se aplican a la repartición prevista en el art. 6", párrafo 2".

"E1 juez puede reducir o suprimir la remuneración si resultara que los salvadores hubiesen, por su culpa, hecho necesario el salvataje o la asistencia o que se hubieren hecho culpables de hurtos, ocultaciones u otros actos fraudulentos".

"Art. 9"-No se debe remuneración alguna por las personas salvadas sin menoscabar, sin embargo, las prescripciones de las leyes nacionales al respecto".

"Los salvadores de vidas humanas que hubieran intervenido en ocasión del accidente que diera lugar al salvataje o a la asistencia tienen derecho a una parte equitativa de la remuneración concedida a los salvadores del buque, del cargamento y de sus accesorios".

"Art. 10.-La acción por pago de la remuneración se prescribe a los dos años, a contar del día en que se hubieran terminado las operaciones de asis_ tencia o salvataje".

"Las causas de suspensión y de interrupción de esta prescripción que. dan determinadas por la ley del tribunal competente en la acción". 
"Las Altas Partes contratantes se reservan el derecho de admitir en sus legislaciones como prorrogador del plazo más arriba indicado el hecho de que el buque asistido o salvado no ha podido ser embargado en las aguas territoriales del Estado en que el demandante tuviera su domicilio o establecimiento principal".

"Art. 11.-Todo capitán está obligado, en tanto que lo pueda hacer sin serio peligro para su buque, equipaje y pasajeros, a prestar asistencia a toda persona, también enemiga, hallada en alta mar, en peligro de sucumbir".

"El propietario del buque no es responsable con respecto a las contravenciones de la disposición precedente".

"Art. 12.-Las Altas Partes Contratantes se comunicarán, a la brevedad posible, las leyes o reglamentos que se hubieran dictado o que estuvieran por dictarse en sus Estados para la ejecución de la disposición que precede".

"Art. 13.-La presente Convención no menoscaba las disposiciones de las legislaciones nacionales o de los Tratados internacionales sobre la orga nización de servicios de asistencia y de salvataje por las autoridadés públi. cas o bajo su control y especialmente sobre el salvataje de los aparejos de pesca".

"Art. 14.-La presente Convención no tiene aplicación a los buques de guerra y a los buques de Estado exclusivamente destinados a un servicio público".

"Art. 15.-Las disposiciones de la presente Convención serán aplicadas con respecto de todos los interesados cuando, ya sea el buque asistente o salvador o el buque asistido o salvado, pertenece a un Estado de una de las Altas Partes contratantes así como en los demás casos previstos por las leyes nacionales".

"Queda sin embargo entendido:

"19.-Que con respecto a los interesados' dependientes de la juris. dicción de un Estado no contratante, la aplicación de dichas disposiciones podrán ser subordinadas, por cada uno de los Estados contratantes, a la con. dición de reciprocidad".

" 2 .-Que cuando todos los interesados dependan de la jurisdicción del mismo Estado que el tribunal competente, se deberá aplicar la ley nacional y no la Convención".

3॰-Que, sin perjuicio de las disposiciones más extensas de las leyes nacionales, el art. 11 tan sólo es aplicable entre los buques de la jurisdicción de los Estados de las Altas Parte contratantes".

"Art. 16.-Cada una de las Altas Partes Contratantes tendrá la facultad de provocar la reunión de una nueva Conferencia después de tres años a contar desde la entrada en vigencia de la presente Convención, con el objeto de buscar las mejoras que pudiesen ser introducidas $y$, especialmente, de extender, si fuera posible, su esfera de aplicación".

"La potencia que hiciere uso de esta facultad deberá notificar su intención a las demás Potencias por medio del Gobierno Belga que se encargará de convocar la Conferencia dentro de los seis meses".

"Art. 17.-Los Estados que no hubiesen firmado la presente Convención pueden, a su petición, adherirse a ella. Esta adhesión será notificada por la vía diplomática al Gobierno Belga y, por éste, a cada uno de los Gobiernos de las otras Partes Contratantes; surtirá sus efectos un mes después del envío de la notificación hecha por el Gobierno Belga". 
"Art. 18.-La presente Convención será ratificada".

"A la expiración del plazo de un año a más tardar, a contar desde el día de la firma de la Convención, el Gobierno Belga se pondrá en contacto con los Gobiernos de las Altas Partes Contratantes que se hubieren declarado dispuestos a ratificarla, a fin de resolver si corresponde ponerla en vigencia".

"Las ratificaciones serán, dado el caso, depositadas inmediatamente en Bruselas y la Convención entrará en vigencia un mes después de este depósito".

"El Protocolo permanecerá abierto durante otro año en favor de los Es. tados representados en la Conferencia de Bruselas. A la expiración de este plazo, sólo podrán adherirse de conformidad con las disposiciones del art. $17 "$.

"Art. 19.-En caso que alguna de las Altas Partes Contratantes denunciara la presente Convención, esta denuncia sólo producirá efecto un año después del dia en que hubiese sido notificada al Gobierno Belga, permaneciendo vigente la Convención entre los demás Contratantes". 